\title{
Radiofrequency bipolar hemostatic sealer reduces blood loss, transfusion requirements, and cost for patients undergoing multilevel spinal fusion surgery: a case control study
}

Steven M Frank ${ }^{1,5^{*}}$, Jack O Wasey ${ }^{1}$, Ian M Dwyer ${ }^{1}$, Ziya L Gokaslan ${ }^{2}$, Paul M Ness ${ }^{3}$ and Khaled M Kebaish ${ }^{4}$

\begin{abstract}
Background: A relatively new method of electrocautery, the radiofrequency bipolar hemostatic sealer (RBHS), uses saline-cooled delivery of energy, which seals blood vessels rather than burning them. We assessed the benefits of RBHS as a blood conservation strategy in adult patients undergoing multilevel spinal fusion surgery.

Methods: In a retrospective cohort study, we compared blood utilization in 36 patients undergoing multilevel spinal fusion surgery with RBHS (Aquamantys ${ }^{\oplus}$, Medtronic, Minneapolis, MN, USA) to that of a historical control group $(n=38)$ matched for variables related to blood loss. Transfusion-related costs were calculated by two methods.

Results: Patient characteristics in the two groups were similar. Intraoperatively, blood loss was $55 \%$ less in the RBHS group than in the control group $(810 \pm 530$ vs. 1,800 $\pm 1,600 \mathrm{~mL} ; p=0.002)$, and over the entire hospital stay, red cell utilization was $51 \%$ less ( $2.4 \pm 3.4$ vs. $4.9 \pm 4.5$ units/patient; $p=0.01)$ and plasma use was $56 \%$ less $(1.1 \pm 2.4$ vs. $2.5 \pm 3.4$ units/patient; $p=0.03$ ) in the RBHS group. Platelet use was $0.1 \pm 0.5$ and $0.3 \pm 0.6$ units/patient in the RBHS and control groups, respectively $(p=0.07)$. The perioperative decrease in hemoglobin was less in the RBHS group than in the control group $(-2.0 \pm 2.2 \mathrm{vs} .-3.2 \pm 2.1 \mathrm{~g} / \mathrm{dL} ; p=0.04)$, and hemoglobin at discharge was higher in the RBHS group ( $10.5 \pm 1.4$ vs. $9.7 \pm 0.9 \mathrm{~g} / \mathrm{dL} ; p=0.01$ ). The estimated transfusion-related cost savings were $\$ 745 /$ case by acquisition cost and approximately 3 - to 5 -fold this amount by activity-based cost.
\end{abstract}

Conclusions: The use of RBHS in patients undergoing multilevel spine fusion surgery can conserve blood, promote higher hemoglobin levels, and reduce transfusion-related costs.

Keywords: Bipolar, Blood, Cautery, Hemostasis, Radiofrequency, Sealer

\section{Background}

Given the recognized risks [1-3] and expense [4,5] of allogeneic blood transfusion in surgical patients, a successful blood management program should include efforts to reduce intraoperative blood loss as a primary measure of blood conservation. Patients undergoing posterior spinal fusion surgery can lose substantial amounts

\footnotetext{
*Correspondence: sfrank3@jhmi.edu

${ }^{1}$ Department of Anesthesiology/Critical Care Medicine, The Johns Hopkins Medical Institutions, Zayed 6208, 1800 Orleans Street, Baltimore, MD 21287, USA

${ }^{5}$ Patient Blood Management Program, Department of Anesthesiology/Critical Care Medicine, The Johns Hopkins Medical Institutions, Zayed 6208, 1800 Orleans Street, Baltimore, MD 21287, USA

Full list of author information is available at the end of the article
}

of blood, which can prolong operative time and obscure visualization of important neural structures. Such patients often require transfusion of allogeneic blood components [6]. Methods to reduce transfusion requirements during spine surgery include controlled hypotension [7], autologous blood salvage $[8,9]$, and antifibrinolytic medications [10]. Another method that has been described recently is a relatively new electrocautery device, which can be described as a saline-irrigated radiofrequency bipolar hemostatic sealer (RBHS). Unlike conventional electrocautery, which burns small blood vessels at temperatures as high as $400^{\circ} \mathrm{C}$, RBHS seals blood vessels by delivering water-cooled energy that causes vascular contraction at a tissue temperature $<100^{\circ} \mathrm{C}[11,12]$. 
Studies have shown that bleeding is reduced when RBHS is used during liver resection [13], total hip arthroplasty [14], and total knee arthroplasty [15]. To our knowledge, only one study has evaluated the utility of RBHS in complex spine surgery. In that study, Mankin et al. [16] reported significant reductions in blood loss $(57 \%)$ and transfusion rates (from $6.6 \%$ to $0 \%$ ) in adolescent patients undergoing surgery for scoliosis; however, they gave only the percentage of patients transfused without reporting the amount of blood transfused or any hemoglobin data. In the current study, we compared blood loss and transfusion requirements in adults undergoing multilevel spinal fusion surgery with RBHS to those of a similar patient cohort in which only conventional unipolar cautery was used. Our blood management program maintains two large databases that accurately monitor both intraoperative and perioperative (entire hospital stay) transfusion of all blood components, including red blood cells (RBCs), fresh frozen plasma (FFP), and platelets (PLTs). Using these databases, we assessed blood loss, transfusion requirements, and estimated transfusion-related costs to assess the utility of RBHS in adult patients undergoing multilevel spinal fusion surgery.

\section{Methods}

After receiving approval from the Johns Hopkins Hospital institutional review board, we performed a retrospective cohort study, whereby 36 consecutive patients undergoing multilevel spinal fusion surgery with the RBHS device (Aquamantys ${ }^{\circ}, M^{2}$ dtronic, Minneapolis, MN, USA) were compared to a historical control group $(n=38)$ that was propensity-matched for important variables related to blood loss. These variables included the number of spinal levels fused, type of surgical procedure (lumbar, thoracic, or thoracolumbar), the nine specific surgeons performing the procedures, and the percentage of patients undergoing revision spinal surgery. Patients in the matched control group were selected from the operating room medical information system (ORMIS) database and underwent surgery between August 2012 and January 2013. Patients in the RBHS group were selected as consecutive surgical cases during July and August of 2013, when the RBHS was introduced. Exclusion criteria were preoperative coagulopathy, thrombocytopenia, and refusal of blood product transfusion.

The RBHS device was set to a power setting of 140, and the saline flow rate was set to medium. Traditional unipolar cautery (ConMed System 5000 ${ }^{\mathrm{mm}}$, Utica, NY, USA) and intraoperative autologous blood salvage (Brat-2, Sorin Group, Milan, Italy) were used in both study groups. An adult-size 225-mL bowl was used for blood salvage, and salvaged blood was processed and transfused if the collected volume exceeded $500 \mathrm{~mL}$. Intraoperative hemoglobin $(\mathrm{Hb})$ triggers were used according to the usual practice at our institution for this type of surgery (9-10 g/dL intraoperatively and $8-9 \mathrm{~g} / \mathrm{dL}$ postoperatively). FFP and PLTs were transfused according to the clinical judgment of the anesthesiologists and surgeons. Typically, FFP and PLTs were given if the transfusion requirements exceeded $1 / 2$ of the patient's total blood volume $(\approx 5$ units RBCs).

Blood utilization data were obtained from two separate databases. Intraoperative data were obtained from the electronic anesthesia records (Metavision', iMdSoft, Needham, MA, USA). A detailed description of this database and its validation have been published previously [6]. Whole hospitalization blood utilization data and hemoglobin data (from admission to discharge) were obtained from a blood management intelligence portal, IMPACT Online ${ }^{\circ}$ (Haemonetics, Braintree, MA, USA) [17]. This database also includes morbidity outcomes based on ICD-9 codes assigned to each patient upon discharge. We compared the following morbidity outcomes between the two groups: infection, thrombotic, renal, respiratory, stroke, and myocardial infarction. We also analyzed a composite outcome that was the presence of any of these morbid events.

We calculated transfusion-related cost by two different methods. The first method is based on the average cost to acquire blood components from blood suppliers in the mid-Atlantic region (acquisition cost). These costs were calculated as \$220/RBC unit, \$50/FFP unit, and $\$ 600 /$ PLT unit. The second method is the activity-based cost of blood, as described by Shander et al. [4], which accounts for every step in the process of bringing blood from the donor to the recipient, including all transfusionrelated activities, such as collection, transport, testing, storage, administrative work, and the transfusion process itself. This cost was determined to be between 3.2 and 4.8 times the acquisition cost. The average incremental equipment cost was $\$ 493$ per surgical case when the RBHS was used.

\section{Sample size and statistical analysis}

We performed a sample size calculation based on the known blood utilization for these types of cases at our institution [6]. To detect a $25 \%$ difference in the number of blood product units transfused with an $\alpha$ of 0.05 and power of 0.8 , we required an estimated sample size of 32 patients per study group.

Differences in the mean measured values between groups were analyzed by Student's $t$ tests. Dichotomous variables were analyzed by the chi-squared test. All tests were two-tailed. All data are presented as mean \pm SD, and $p<0.05$ was used to define significance.

\section{Results}

Preoperative and intraoperative patient characteristics The RBHS and control groups were similar for the variables of age, sex, body mass, number of spinal levels fused, and 
Table 1 Comparison of the radiofrequency bipolar hemostatic sealer and control groups

\begin{tabular}{llll}
\hline Variable & RBHS group $(\boldsymbol{n}=\mathbf{3 6})$ & Control group $(\boldsymbol{n}=\mathbf{3 8})$ & $\boldsymbol{P}$ value \\
\hline Age (years) & $64 \pm 14$ & $59 \pm 13$ & 0.17 \\
Sex (male/female) & $18 / 18$ & $23 / 15$ & 0.33 \\
Body mass (kg) & $76.6 \pm 18.4$ & $74.1 \pm 21.2$ & 0.62 \\
Spinal levels fused (median (IQR)) & $4(3,9)$ & $4(2,7)$ & 0.23 \\
Spinal levels fused (mean \pm SD) & $6.1 \pm 4.5$ & $4.9 \pm 3.7$ & 0.22 \\
Thoracic fusion & $4(11.1 \%)$ & $4(10.5 \%)$ & 0.67 \\
Lumbar fusion & $18(50 \%)$ & $20(52.6 \%)$ & 0.56 \\
Thoracolumbar fusion & $14(38.9 \%)$ & $14(36.9 \%)$ & 0.72 \\
Surgeon specialty (neuro/ortho) & $12 / 24$ & $12 / 26$ & 0.52 \\
Duration of surgery (h) & $6.07 \pm 0.42$ & $6.14 \pm 0.37$ & 0.89 \\
Revision surgery & $8(22.2 \%)$ & $7(18.4 \%)$ & 0.78 \\
ASA class & $2.7 \pm 0.1$ & $2.5 \pm 0.1$ & 0.19 \\
\hline ASA Amican Soct
\end{tabular}

ASA American Society of Anesthesiologists, IQR interquartile range, RBHS radiofrequency bipolar hemostatic sealer, SD standard deviation, Neuro neurosurgery, Ortho orthopedic surgery.

preoperative hemoglobin (Table 1). The percentages of patients undergoing thoracic, lumbar, and thoracolumbar fusion and the percentage of patients undergoing revision surgery were also similar in the two groups. Surgeon specialty (neurosurgery/orthopedic surgery) and duration of surgery were similar between groups.

\section{Blood loss and hemoglobin levels}

Intraoperatively, estimated blood loss was $55 \%$ less in the RBHS group than in the control group $(p=0.002)$. Likewise, the volume of colloid used was $63 \%$ less $(p=0.04)$, and the volume of returned salvaged blood was $54 \%$ less $(p=0.003)$ in the RBHS group than that in the control group (Table 2). The nadir hemoglobin during hospitalization and the hemoglobin upon discharge were higher in the RBHS group (Table 2). The decrease in hemoglobin from admission to discharge was $1.2 \mathrm{~g} / \mathrm{dL}$ less in the RBHS group than that in the control group $(p=0.04)$, and the hemoglobin concentration at discharge was $0.8 \mathrm{~g} / \mathrm{dL}$ higher in the RBHS group $(p=0.01)$ than that in the control group. These changes in hemoglobin levels are summarized in Figure 1.

\section{Transfusion requirements}

We also compared the transfusion requirements in the two groups (Table 3). Intraoperatively, the RBHS group required $57 \%$ fewer units of $\operatorname{RBCs}(p=0.009)$ and $83 \%$ fewer units of FFP $(p=0.002)$ than did the control group. The two groups did not differ significantly in PLT requirements. Over the entire hospital stay, the RBHS group received $51 \%$ fewer units of $\operatorname{RBCs}(p=0.01)$ and $56 \%$ fewer units of FFP $(p=0.03)$ than did the control group (Figure 2). Although the RBHS group received fewer platelets than the control group did, the difference was not statistically significant $(p=0.07)$.

\section{Outcome data}

The incidence of morbid events and the composite outcome of any morbid event were similar in the two groups (Table 4). The difference in length of stay was

Table 2 Comparison of the radiofrequency bipolar hemostatic sealer and control groups

\begin{tabular}{|c|c|c|c|}
\hline Variable & RBHS group $(n=36)$ & Control group $(n=38)$ & $P$ value \\
\hline Hemoglobin, preoperative (g/dL) & $12.5 \pm 2.1$ & $12.9 \pm 2.1$ & 0.47 \\
\hline Hemoglobin, hospital nadir (g/dL) & $9.4 \pm 1.6$ & $8.5 \pm 1.1$ & 0.01 \\
\hline Hemoglobin upon discharge (g/dL) & $10.5 \pm 1.4$ & $9.7 \pm 0.9$ & 0.01 \\
\hline$\Delta$ Hemoglobin (admit - discharge) (g/dL) & $-2.0 \pm 2.2$ & $-3.2 \pm 2.1$ & 0.04 \\
\hline Crystalloid (mL) & $6,000 \pm 2,000$ & $5,900 \pm 2,300$ & 0.88 \\
\hline Colloid volume (mL) & $70 \pm 170$ & $190 \pm 270$ & 0.04 \\
\hline Cell salvage (volume returned $(\mathrm{mL})$ ) & $230 \pm 47$ & $500 \pm 200$ & 0.003 \\
\hline Estimated blood loss (mL) & $810 \pm 530$ & $1,800 \pm 1,600$ & 0.002 \\
\hline
\end{tabular}

RBHS radiofrequency bipolar hemostatic sealer. 


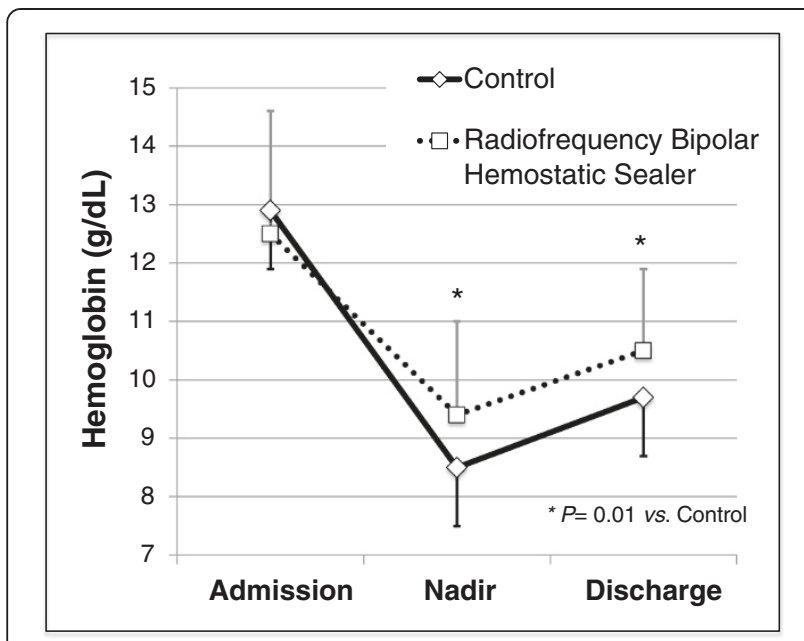

Figure 1 Average hemoglobin concentrations compared in the radiofrequency bipolar hemostatic sealer (RBHS) and control groups. Baseline hemoglobin was similar between groups, but the decrease in hemoglobin was less in the RBHS group $(P=0.04)$, and the hemoglobin at discharge was higher in the RBHS group $(P=0.01)$.

not statistically significant $(6.8 \pm 4.1$ days in the RBHS group and $8.1 \pm 6.4$ days in the control group; $p=0.35$ ).

\section{Cost savings}

When we multiplied the acquisition costs for each unit of blood component in US dollars by the number of units saved (difference between groups) during the entire hospital stay, we found that use of the RBHS device saved an average blood cost of $\$ 745 /$ patient (Table 5). Using the activity-based blood costs [4], the cost savings attributable to the RBHS were between $\$ 2,384$ and $\$ 3,576 /$ patient. After accounting for the RBHS device cost, the net cost savings were $\$ 252 /$ patient (using the blood acquisition cost), and $\$ 1,891-\$ 3,083 /$ patient (using the activitybased cost). This however, does not include any incremental costs of evaluating and/or treating transfusion-related complications.

\section{Discussion}

For patients undergoing multilevel spine fusion surgery, the use of RBHS to achieve hemostasis significantly reduced blood loss, transfusion requirements, the decrease in $\mathrm{Hb}$, and cost. These findings demonstrate the effectiveness of RBHS for blood conservation in patients undergoing these complex surgeries. Average blood loss was approximately $40 \%$ of total blood volume in the control group but less than $20 \%$ of total blood volume in the treatment group. Although various methods of blood conservation have been described for orthopedic and spine surgery (controlled hypotension [7], autologous blood salvage (cell saver) $[8,9]$, autologous intraoperative normovolemic hemodilution [18], and antifibrinolytic medications [10]), little published evidence has described the beneficial effects of new methods of electrocautery for achieving hemostasis. It is noteworthy that in addition to reducing blood loss and transfusion, the use of RBHS also reduced the variation in bleeding and transfusion to as little as one-third to one-half that in the control group, as assessed by standard deviation of the means for these factors. This finding suggests that RBHS may be useful in reducing blood loss for spinal fusion patients predisposed to the greatest amount of bleeding.

Table 3 Intraoperative and whole hospitalization transfusion requirements

\begin{tabular}{llll}
\hline Variable & RBHS group $(\boldsymbol{n}=\mathbf{3 6})$ & Control group $(\boldsymbol{n}=\mathbf{3 8})$ & P value \\
\hline Transfusion (intraoperative) & & & $2.8 \pm 3.4$ \\
RBC (units/patient) & $1.2 \pm 1.4$ & $1.8 \pm 2.8$ & 0.009 \\
FFP (units/patient) & $0.3 \pm 0.7$ & $0.1 \pm 0.4$ & 0.002 \\
PLTs (units/patient) & $0 \pm 0$ & $24(63 \%)$ & 0.11 \\
RBCs given & $19(53 \%)$ & $16(42 \%)$ & 0.48 \\
FFP given & $7(19 \%)$ & $3(8 \%)$ & 0.03 \\
PLTs given & $0(0 \%)$ & & 0.24 \\
Transfusion (whole hospital stay) & & $4.9 \pm 4.5$ & 0.01 \\
RBC (units/patient) & $2.4 \pm 2.4$ & $2.5 \pm 3.4$ & 0.03 \\
FFP (units/patient) & $1.1 \pm 2.4$ & $0.3 \pm 0.6$ & 0.07 \\
PLTs (units/patient) & $0.1 \pm 0.5$ & $30(79 \%)$ & 0.05 \\
RBCs given & $21(58 \%)$ & $6(42 \%)$ & 0.04 \\
FFP given & $7(19 \%)$ & $3(8 \%)$ & 0.24 \\
PLTs given & $0(0 \%)$ & & \\
\hline
\end{tabular}

FFP fresh frozen plasma, $P L T s$ platelets, $R B C$ red blood cells, $R B H S$ radiofrequency bipolar hemostatic sealer. 


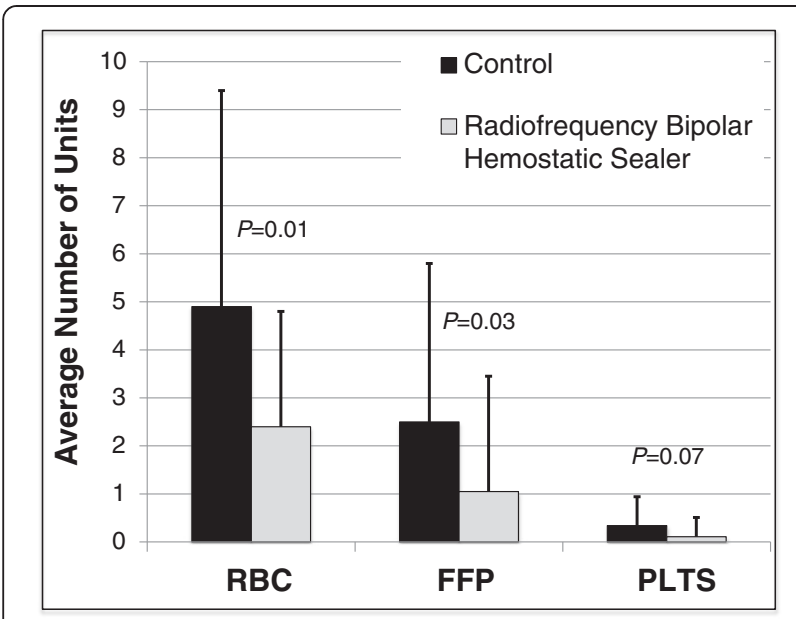

Figure 2 Blood utilization (from admission to discharge) compared in the radiofrequency bipolar hemostatic sealer (RBHS) and control groups. Compared to the control group, the RBHS group used $51 \%$ fewer units of red blood cells $(P=0.01)$ and $56 \%$ fewer units of fresh frozen plasma $(P=0.03)$. The RBHS group also used fewer platelets (PLTS), but the difference from control did not reach statistical significance $(P=0.07)$.

Traditional unipolar cautery produces hemostasis by burning tissue at temperatures up to $400^{\circ} \mathrm{C}$ [12]. In contrast, the RBHS method of cautery uses saline-cooled bipolar delivery of radiofrequency energy, which contracts and seals small blood vessels [19] at tissue temperature $<100^{\circ} \mathrm{C}[14,20,21]$. Some evidence also supports the efficacy of RBHS for hemostasis during bleeding from bone surfaces, by way of shrinking collagen in the walls of blood vessels [22]. Because the temperature is reduced by saline irrigation, RBHS causes less charring of the tissues and less injury to neural tissues [11], an important factor during spinal surgery. Advantages of

Table 4 Comparison of clinical outcomes in the radiofrequency bipolar hemostatic sealer and control groups

\begin{tabular}{llll}
\hline Variable & $\begin{array}{l}\text { RBHS group } \\
(\boldsymbol{n}=\mathbf{3 6})\end{array}$ & $\begin{array}{l}\text { Control group } \\
(\boldsymbol{n}=\mathbf{3 8})\end{array}$ & $\boldsymbol{P}$ value \\
\hline $\begin{array}{l}\text { Composite outcome } \\
\text { (any morbid event) }\end{array}$ & $1(2.8)$ & $5(13.1)$ & 0.20 \\
$\begin{array}{l}\text { Morbid events } \\
\text { a }\end{array}$ & $0(0 \%)$ & $1(2.8 \%)$ & 0.20 \\
Infection & $1(2.8 \%)$ & $2(5.3 \%)$ & 0.87 \\
Thrombotic & $1(2.8 \%)$ & $2(5.3 \%)$ & 0.87 \\
Renal & $0(0 \%)$ & $0(0 \%)$ & $\mathrm{NS}$ \\
Respiratory & $0(0 \%)$ & $0(0 \%)$ & $\mathrm{NS}$ \\
Stroke & $0(0 \%)$ & $0(0 \%)$ & $\mathrm{NS}$ \\
\hline Myocardial infarction & & & \\
\hline
\end{tabular}

NS not significant, RBHS radiofrequency bipolar hemostatic sealer. ${ }^{\mathrm{a}}$ Morbid events were determined by ICD-9 codes at patient discharge from IMPACT Online (Haemonetics Corp, Braintree, MA, USA).
Table 5 Units of blood product saved and costs saved per surgical case

\begin{tabular}{llll}
\hline Blood component & Units & Acquisition cost $^{\text {a }}$ & ${\text { Activity-based } \text { cost }^{\mathbf{b}}}^{\text {A }^{2}}$ \\
\hline Savings in RBCS & 2.5 & $\$ 550$ & $\$ 1,760-\$ 2,640$ \\
Savings in FFP & 1.4 & $\$ 75$ & $\$ 240-\$ 360$ \\
Savings in PLTs & 0.2 & $\$ 120$ & $\$ 384-\$ 576$ \\
Blood cost savings & & $\$ 745$ & $\$ 2,384-\$ 3,576$ \\
Net cost savings & & $\$ 252$ & $\$ 1,891-\$ 3,083$ \\
\hline
\end{tabular}

FFP fresh frozen plasma, PLTs platelets, RBCs red blood cells, RBHS radiofrequency bipolar hemostatic sealer. ${ }^{a}$ Calculated as $\$ 220 /$ RBC unit, $\$ 50 /$ FFP unit, and $\$ 600 / \mathrm{PLT}$ unit, the average cost of blood components in the mid-Atlantic region. ${ }^{\mathrm{b}}$ Calculated as 3.2 to 4.8 times acquisition cost [4]. 'Calculated as blood cost savings minus RBHS device costs (\$493).

achieving better hemostasis during spine surgery are not limited to reducing transfusion requirements. Better visualization of the delicate neural structures may result in better surgical outcomes; however, assessing this outcome would require a larger sample size, as neurologic injury is a relatively uncommon event.

Previous studies in total joint replacement [14,23], liver resection [13], and scoliosis surgery [16] have reported reductions in bleeding and transfusion by amounts similar to those determined in our study. In the one study that showed no difference in blood loss or transfusion requirements with the use of RBHS in patients undergoing total hip arthroplasty, the RBHS device was used alone, without concomitant use of unipolar cautery, and the overall transfusion rates were very low $(4 \%-6 \%)$ [23]. In our study, transfusion rates were high, owing to the complex spine procedures, and both types of cautery were used; our surgeons agree that for these procedures, both are needed. These findings suggest that RBHS may not be an adequate substitute for unipolar cautery during highly complex surgical procedures.

In addition to confirming the effectiveness of RBHS in spinal fusion surgery, we showed that patients have a substantially higher hemoglobin level at discharge when RBHS is used. Although the difference in morbidity outcomes and length of stay in our study were not statistically significant between groups, our study was not powered with a large enough sample size to adequately compare these outcomes. However, we did see a trend toward more favorable overall outcomes in the RBHS group. Considering the known association between allogeneic blood transfusion and increased morbidity and length of stay [1-3], it is conceivable that with a larger sample size, improved outcomes may become apparent when RBHS is used.

The use of RBHS for these complex spinal procedures led to significant cost savings because of the reduction in transfusion requirements. The method of calculating cost savings is clear when blood product acquisition costs are utilized. The activity-based costs, however, account for the many steps in the process of bringing blood all the 
way from the donor to the recipient. Admittedly, this method inflates the cost of blood, but each step does indeed add incremental cost at some level for management of the blood supply [4].

Our study had several limitations that should be recognized. First, the study design was retrospective in that it used a historical control group. To guard against bias, however, we chose consecutive patients for whom the RBHS device was used and propensity matched these patients to control patients based on clinical predictors of blood loss and transfusion. The patient characteristics (Table 1) illustrate that the two groups were comparable. Second, one particular outcome that we report, intraoperative estimated blood loss, is known to be a relatively inaccurate measure of actual bleeding [24] for a variety of reasons (irrigation in the suction container, blood on sponges, and blood on the floor and surgical drapes). However, because of the retrospective nature of the study, the clinicians who estimated blood loss were unaware of and uninvolved with the study and thus less likely to introduce bias in measuring this parameter. A particular strength in our study was the use of two comprehensive databases that have been previously validated $[6,17]$ to obtain both intraoperative and whole-hospital-stay blood utilization data. Previous studies focused primarily on intraoperative blood loss and transfusion alone [16,25]. Our databases include whole hospital (from admission to discharge) nadir and discharge hemoglobin levels and utilization of both RBC and non-RBC blood components (FFP and PLTs).

\section{Conclusions}

For patients undergoing multilevel lumbar, thoracic, or thoracolumbar spinal fusion surgery, the use of RBHS to achieve hemostasis results in reduced blood loss, reduced intraoperative and whole hospitalization transfusion requirements, higher discharge hemoglobin levels, and substantial cost savings. These findings suggest that using this new method as part of a comprehensive patient blood management program is an efficacious strategy.

\section{Abbreviations}

FFP: Fresh frozen plasma; Hb: Hemoglobin; ORMIS: Operating room medical information system; PLTS: Platelets; RBC: Red blood cells;

RBHS: Radiofrequency bipolar hemostatic sealer.

\section{Competing interests}

Steven M. Frank, MD, has received honoraria for speaking at educational seminars from the following companies: CSL Behring, Haemonetics, and Medtronic. These companies are all involved with patient blood management. Zia L. Gokaslan holds stock in Spinal Kinetics and U.S. Spine and received grants and research funds from DuPuy, AO North America, Integra, NREF, and Medtronic and honoraria and fellowship support from AO Spine North America. Khaled M. Kebaish has consulted for K2M and DePuy Spine, has had speaking/teaching arrangements with K2M and DePuy Spine, and has received research support (investigator salary) from K2M (paid directly to institution/employer) and DePuy Spine (paid directly to institution/employer).

\section{Authors' contributions}

SF was involved with design of the study, statistical analysis, and with manuscript preparation. JW was involved with the data interpretation, statistical analysis, and manuscript preparation. ID assisted with data collection and analysis. ZG, PN, and KK assisted with data interpretation and manuscript preparation. All authors read and approved the final manuscript.

\section{Authors' information}

SF is the Medical Director of the Patient Blood Management Program at Johns Hopkins Hospital. ZG is the Chief of Spine Surgery at Johns Hopkins Hospital. PM is the Director of Transfusion Medicine at the Johns Hopkins Hospital.

\section{Acknowledgements}

Support was provided from institutional and/or departmental sources and from the New York Community Trust (New York, NY). There was no industry support for this study. The authors would like to thank Claire Levine for editorial assistance and Sharon Paul for assistance with data acquisition.

\section{Author details}

'Department of Anesthesiology/Critical Care Medicine, The Johns Hopkins Medical Institutions, Zayed 6208, 1800 Orleans Street, Baltimore, MD 21287, USA. ${ }^{2}$ Department of Neurosurgery, Oncology, and Orthopaedic Surgery, The Johns Hopkins Medical Institutions, Zayed 6208, 1800 Orleans Street, Baltimore, MD 21287, USA. ${ }^{3}$ Department of Pathology, The Johns Hopkins Medical Institutions, Zayed 6208, 1800 Orleans Street, Baltimore, MD 21287, USA. ${ }^{4}$ Department of Orthopaedic Surgery, The Johns Hopkins Medical Institutions, Zayed 6208, 1800 Orleans Street, Baltimore, MD 21287, USA. ${ }^{5}$ Patient Blood Management Program, Department of Anesthesiology/Critical Care Medicine, The Johns Hopkins Medical Institutions, Zayed 6208, 1800 Orleans Street, Baltimore, MD 21287, USA.

Received: 14 April 2014 Accepted: 16 June 2014

Published online: 05 July 2014

\section{References}

1. Koch CG, Li L, Duncan Al, Mihaljevic T, Loop FD, Starr NJ, Blackstone EH: Transfusion in coronary artery bypass grafting is associated with reduced long-term survival. Ann Thorac Surg 2006, 81(5):1650-1657.

2. Rubinstein C, Davenport DL, Dunnagan R, Saha SP, Ferraris VA, Xenos ES: Intraoperative blood transfusion of one or two units of packed red blood cells is associated with a fivefold risk of stroke in patients undergoing elective carotid endarterectomy. J Vasc Surg 2013, 57(2 Suppl):53S-57S.

3. Glance LG, Dick AW, Mukamel DB, Fleming FJ, Zollo RA, Wissler R, Salloum R, Meredith UW, Osler TM: Association between intraoperative blood transfusion and mortality and morbidity in patients undergoing noncardiac surgery. Anesthesiology 2011, 114(2):283-292.

4. Shander A, Hofmann A, Ozawa S, Theusinger OM, Gombotz H, Spahn DR: Activity-based costs of blood transfusions in surgical patients at four hospitals. Transfusion 2010, 50(4):753-765.

5. Reeves BC, Murphy GJ: Increased mortality, morbidity, and cost associated with red blood cell transfusion after cardiac surgery. Curr Opin Cardiol 2008, 23(6):607-612.

6. Frank SM, Savage WJ, Rothschild JA, Rivers RJ, Ness PM, Paul SL, Ulatowski JA: Variability in blood and blood component utilization as assessed by an anesthesia information management system. Anesthesiology 2012, 117(1):99-106

7. Paul JE, Ling E, Lalonde C, Thabane L: Deliberate hypotension in orthopedic surgery reduces blood loss and transfusion requirements: a meta-analysis of randomized controlled trials. Can J Anaesth 2007, 54(10):799-810.

8. Waters JH, Dyga RM, Waters JF, Yazer MH: The volume of returned red blood cells in a large blood salvage program: where does it all go? Transfusion 2011, 51(10):2126-2132.

9. Williamson KR, Taswell HF: Indications for intraoperative blood salvage. J Clin Apher 1990, 5(2):100-103.

10. Alvarez JC, Santiveri FX, Ramos I, Vela E, Puig L, Escolano F: Tranexamic acid reduces blood transfusion in total knee arthroplasty even when a blood conservation program is applied. Transfusion 2008, 48(3):519-525. 
11. Donzelli J, Leonetti JP, Wurster RD, Lee JM, Young MR: Neuroprotection due to irrigation during bipolar cautery. Arch Otolaryngol Head Neck Surg 2000, 126(2):149-153.

12. Bovie WT: A preliminary note on a new surgical-current generator. Clin Orthopaed Rel Res 1928, 1995(310):3-5.

13. Geller DA, Tsung A, Maheshwari V, Rutstein LA, Fung JJ, Marsh JW: Hepatic resection in 170 patients using saline-cooled radiofrequency coagulation. HPB (Oxford) 2005, 7(3):208-213.

14. Marulanda GA, Ulrich SD, Seyler TM, Delanois RE, Mont MA: Reductions in blood loss with a bipolar sealer in total hip arthroplasty. Expert Rev Med Devices 2008, 5(2):125-131.

15. Marulanda GA, Ragland PS, Seyler TM, Mont MA: Reductions in blood loss with use of a bipolar sealer for hemostasis in primary total knee arthroplasty. Surg Technol Int 2005, 14:281-286.

16. Mankin KP, Moore CA, Miller LE, Block JE: Hemostasis with a bipolar sealer during surgical correction of adolescent idiopathic scoliosis. J Spinal Disord Tech 2012, 25(5):259-263.

17. Frank SM, Resar LM, Rothschild JA, Dackiw EA, Savage WJ, Ness PM: A novel method of data analysis for utilization of red blood cell transfusion. Transfusion 2013, 53:3052-3059.

18. Goodnough LT, Despotis GJ, Merkel K, Monk TG: A randomized tria comparing acute normovolemic hemodilution and preoperative autologous blood donation in total hip arthroplasty. Transfusion 2000, 40(9):1054-1057.

19. Gorisch W, Boergen KP: Heat-induced contraction of blood vessels. Lasers Surg Med 1982, 2(1):1-13.

20. Poon RT, Fan ST, Wong J: Liver resection using a saline-linked radiofrequency dissecting sealer for transection of the liver. J Amer Coll Surg 2005, 200(2):308-313.

21. Donzelli J, Leonetti JP, Bergstrom R, Wurster RD, Young MR:

Thermoprotective mechanisms of irrigation during bipolar cautery. Otolaryngol Head Neck Surg 1998, 119(3):153-158.

22. Chen SS, Wright NT, Humphrey JD: Heat-induced changes in the mechanics of a collagenous tissue: isothermal, isotonic shrinkage. J Biomech Eng 1998, 120(3):382-388.

23. Morris MJ, Barrett M, Lombardi AV Jr, Tucker TL, Berend KR: Randomized blinded study comparing a bipolar sealer and standard electrocautery in reducing transfusion requirements in anterior supine intermuscular total hip arthroplasty. J Arthroplasty 2013, 28(9):1614-1617.

24. Bose $P$, Regan F, Paterson-Brown S: Improving the accuracy of estimated blood loss at obstetric haemorrhage using clinical reconstructions. BJOG 2006, 113(8):919-924.

25. Takatsuki M, Eguchi S, Yamanouchi K, Tokai H, Hidaka M, Soyama A, Miyazaki K, Hamasaki K, Tajima Y, Kanematsu T: Two-surgeon technique using saline-linked electric cautery and ultrasonic surgical aspirator in living donor hepatectomy: its safety and efficacy. Am J Surg 2009, 197(2):e25-e27.

doi:10.1186/s13018-014-0050-2

Cite this article as: Frank et al:: Radiofrequency bipolar hemostatic sealer reduces blood loss, transfusion requirements, and cost for patients undergoing multilevel spinal fusion surgery: a case control study. Journal of Orthopaedic Surgery and Research 2014 9:50.

\section{Submit your next manuscript to BioMed Central and take full advantage of:}

- Convenient online submission

- Thorough peer review

- No space constraints or color figure charges

- Immediate publication on acceptance

- Inclusion in PubMed, CAS, Scopus and Google Scholar

- Research which is freely available for redistribution

Submit your manuscript at www.biomedcentral.com/submit
C Biomed Central 